\title{
Removal of ammonium nitrogen in the subsiding water from cropland in the Yellow River irrigation area of Ningxia by natural zeolite
}

\author{
Cuiling Zhang ${ }^{1, ~ a, ~ H o n g f a n g ~ W a n g ~}{ }^{1, b}$, Qing Chang ${ }^{1, c}$ and Jiali Zhang ${ }^{1, d}$ \\ ${ }^{1}$ School of Environmental and Municipal Engineering, Lanzhou Jiaotong University, Lanzhou 730070, \\ China \\ a zhangcuiling@mail.Izjtu.cn, \\ b1825000828@qq.com, \\ c changq47@ mail.Izjtu.cn, \\ d515745010@qq.com
}

\begin{abstract}
Keywords: natural zeolite; adsorption; ammonium-nitrogen; irrigation drainage.
Abstract. Aimed at the distinguishing features, namely, high salinity, high $\mathrm{pH}$ value, unstable water quality and quantity, of the subsiding water from cropland in the Yellow River irrigation area of Ningxia, static adsorption experiments were carried out to remove ammonium nitrogen from the aqueous solution by natural zeolite. The ammonium adsorption onto natural zeolite is a $\mathrm{pH}$-dependent process, and the appropriate range of $\mathrm{pH}$ value for ammonium removal by zeolite is from 5 to 9 . The presence of co-existing ions in the solution could reduce the uptake of ammonium onto the zeolite. The orders of cations and anions effect on ammonium removal are $\mathrm{K}^{+}>\mathrm{Na}^{+}>\mathrm{Ca}^{2+}>\mathrm{Mg}^{2+}$ and $\mathrm{SO}_{4}{ }^{2-}>$ $\mathrm{NO}_{3}{ }^{-}>\mathrm{Cl}^{-}>\mathrm{H}_{2} \mathrm{PO}_{4}{ }^{-}$, respectively. Based on the obtained experimental results, it can be concluded that the natural zeolite has great potential in cost-effective removal of ammonium of the irrigation drainage in the Yellow River irrigation area of Ningxia.
\end{abstract}

\section{Introduction}

Nitrogen is one of the essential elements for plants, the lack of which in soils often limits agricultural production. However, excessive use of chemical nitrogen fertilizers causes serious environmental hazards as only a fraction of nitrogen used is really absorbed and utilized by the crop. The excess fertilizer is washed off leading to high concentrations of elements such as nitrogen, phosphorus, and potassium in surface water bodies[1]. The increase of nitrogen compounds would accelerate eutrophication of rivers and lakes[2].

Yellow River irrigation area of Ningxia located on the northwest of Loess highland of China. Because of low precipitation and high evaporation, drought is the main feature of the climate in this region. The average annual rainfall is less than $200 \mathrm{~mm}$ but the average annual evaporation is about $1700 \mathrm{~mm}[3]$. As the Yellow River passing through this region, Ningxia irrigation area enjoys a convenient irrigation-drainage system with about 200 drainage ditches. The average annual irrigation water is about $70 \times 10^{8} \mathrm{~m}^{3}$, and the amount of irrigation drainage is about $40 \times 10^{8} \mathrm{~m}^{3}$ [4]. Excessive use of nitrogen fertilizer causes the increase of ammonium nitrogen $\left(\mathrm{NH}_{4}{ }^{+}-\mathrm{N}\right)$ in the subsiding water from cropland into the Yellow River, which has become one of the main water pollution sources of Yellow River [5]. The subsiding water from cropland in Ningxia irrigation area has following particular features. The average degree of mineralization is very high and reaches up to $1740 \mathrm{mg} / \mathrm{L}$; the concentration of ammonium nitrogen lies in the range of $3.73 \sim 26.63 \mathrm{mg} / \mathrm{L}$; the concentration of total phosphorus is in the range of $0.13 \sim 1.95 \mathrm{mg} / \mathrm{L}$; the $\mathrm{pH}$ value is comparatively high and lies in the range of 8.0 8.8. In addition, the water quality and quantity change with seasonal variation. Based on these characteristics, exploring the suitable and efficient methods to remove ammonium nitrogen is meaningful and great importance.

Although there are large number of methods for the removal of ammonium ions at present, such as air stripping, breakpoint chlorination, biological nitrification and denitrification, chemical precipitation, adsorption and ion exchange, etc, the characteristics of the subsiding water of the Ningxia irrigation areas mentioned above make the adsorption and ion exchange method become suitable and effective. Zeolite as one of the important adsorbent has been researched for decades for the removal of ammonium ions because of large specific surface area, high cation exchange capacity 
(CEC) and great cation selectivity[6,7]. What's more, nitrogen saturated zeolite can be used as a nitrogen fertilizer without regeneration rather than the toxic admixtures normally present in sewage. Presently, a number of studies related to the removal of ammonium from aqueous solution using different zeolites have been reported and the effects of zeolite dosage, particle size, initial concertration, $\mathrm{pH}$ and temperature on ammonium adsorption capacity have been researched extensively[2,8,9]. By comparing previous studies, we may draw the conclusion that the zeolite of different sources has different capacity to remove ammonium, every special zeolite material requires individual research[10,11].In particular, the objective of this study was to use Baiyin zeolite to remove the ammonium nitrogen in the subsiding water from cropland of Yellow River irrigation area in Ningxia. Baiyin city, near Ningxia, is rich in zeolite, we can get the required massive zeolite conveniently and economically.

In this study, the zeolite was characterized by X-ray Diffraction (XRD) and X-ray Fluorescence (XRF) firstly, and the basic porous structure parameters of zeolite were determined; The adsorption mechanism of ammonium on zeolite were examined in detail by the adsorption isotherms and the adsorption kinetics; the effects of coexisting substance and $\mathrm{pH}$ value on adsorption behavior were discussed based on the water quality status of the Yellow River irrigation area in ningxia.

\section{Materials and method}

Materials and chemicals. The natural zeolite (brick red) was obtained from Baiyin, Gansu Province, P. R. China, and was prepared through crushing, sieving (20 120 mesh), washing with deionized water and air-drying. Stock solutions of the ammonium ions were prepared from analytical grade ammonium chloride $\left(\mathrm{NH}_{4} \mathrm{Cl}\right)$. All chemicals used in the study, such as potassium chloride $(\mathrm{KCl})$, etc., are analytical grade, and deionized water is used throughout the experiments.

Characteristics of zeolite samples. In order to confirm the crystal structure and the mineralogy of the zeolite, X-ray diffraction (XRD) analysis was performed using $\mathrm{Cu} \mathrm{K} \alpha$ radiation. The tube voltage was $40 \mathrm{kV}$, and the current was $60 \mathrm{~mA}$. The XRD diffraction patterns were taken in the range of $3 \sim 75^{\circ}$ at a scan speed of $0.02^{\circ} \cdot \mathrm{s}^{-1}$. Phase identification was carried out by comparison with those included in the Joint Committee of Powder Diffraction Standards (JCPDSs) database. (Fig.1). Chemical composition of the zeolite samples was determined using X-ray fluorescence (XRF). The specific surface area (BET), pore volume and diameter of zeolite samples were determined at P/P0 0.995 by nitrogen gas adsorption analyzer.

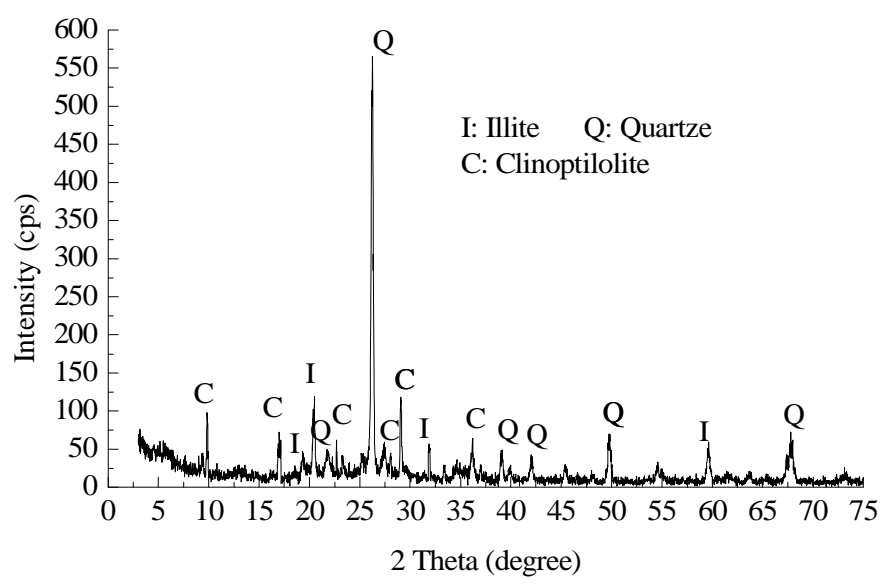

Fig. 1. X-ray diffractogram of powder zeolite.

Zeolites found in nature are rarely in their pure form but usually contain impurities such as other types of zeolite, other minerals or amorphous materials[12]. In this case, clinoptilolite, illite and quartz are the main mineral species in natural zeolite as indicated by the XRD pattern. 
Table 1 shows that natural zeolite mainly consists of silicium and aluminum with mole ratio of $\mathrm{Si} / \mathrm{Al}$ of 4.53. Results of the chemical analysis also show that natural zeolite contains a complement of exchangeable cations such as $\mathrm{Ca}^{2+}, \mathrm{K}^{+}, \mathrm{Mg}^{2+}, \mathrm{Na}^{+}$and $\mathrm{Fe}^{3+}$. These cations have important roles in ion-exchange with other cations in solution such as ammonium. The BET parameters can be seen from Table 1.

Table1 Composition and BET parameters of the zeolite

\begin{tabular}{ccccll}
\hline $\begin{array}{l}\text { Chemical } \\
\text { elements }\end{array}$ & Weight $(\%)$ & $\begin{array}{l}\text { Chemical } \\
\text { elements }\end{array}$ & Weight $(\%)$ & BET parameters & Value \\
\hline $\mathrm{Si}$ & 52.48 & $\mathrm{~K}$ & 3.99 & Surface $\operatorname{area}\left(\mathrm{m}^{2} . \mathrm{g}^{-1}\right)$ & 9.29 \\
$\mathrm{Al}$ & 11.16 & $\mathrm{Na}$ & 3.39 & Total pore volume $\left(\mathrm{cm}^{3} . \mathrm{g}^{-1}\right)$ & 0.029 \\
$\mathrm{Fe}$ & 14.55 & $\mathrm{Sr}$ & 2.74 & Average pore width $(\mathrm{nm})$ & 12.51 \\
$\mathrm{Ca}$ & 5.83 & $\mathrm{Ru}$ & 1.20 & & \\
$\mathrm{Mg}$ & 2.18 & Others & 2.48 & & \\
\hline
\end{tabular}

Adsorption experiments. A series of adsorption experiments were carried out by batch method under different conditions. For each batch adsorption experiment, $0.5 \mathrm{~g}$ of $60 \sim 70$ mesh zeolite was firstly added into the conical flask containing $100 \mathrm{~mL}$ of a prescribed initial concentration of $\mathrm{NH}_{4}{ }^{+}$ solution at desired $\mathrm{pH}$ level (adjusted using $0.1 \mathrm{~mol} / \mathrm{L} \mathrm{HCl}$ or $\mathrm{NaOH}$ solution). Then the conical flask was shaken at $200 \mathrm{rpm}$ and kept for $300 \mathrm{~min}$, at this time, the adsorption of ammonia nitrogen by zeolite has reached equilibrium state. [13]At the same time, the temperature was controlled at $308 \mathrm{~K}$ in the thermostatic shaker (THZ-82A, China). After centrifugation, the supernatant solutions were assessed by the standard Nesslerization method using a visible spectrophotometer. The uptake of ammonium was calculated from the decrease of ammonium concentrations relative to the initial concentration. All tests were done in triplicate with average data reported.

The adsorption performance was evaluated by the amount of ammonium absorbed on per unit mass of zeolite ( $\mathrm{q}$ in $\mathrm{mg}-\mathrm{N} / \mathrm{g}$ ) and removal efficiency ( $\mathrm{E}$ in \%), which could be calculated according to Eq. 1 and Eq.2, respectively. where $\mathrm{C}_{0}$ and $\mathrm{C}_{\mathrm{e}}$ are the initial and equilibrium ammonium concentrations (mg-N/L), respectively. V is the ammonium solution volume ( $\mathrm{L}$ ) and $\mathrm{M}$ is the mass of zeolite used (g).

$$
\begin{aligned}
& q_{e}=\frac{V\left(C_{0}-C_{e}\right)}{M} \\
& E=\frac{C_{0}-C_{e}}{C_{0}} \times 100
\end{aligned}
$$

\section{Result and discussion}

Effect of pH Values. $\mathrm{pH}$ value has significant effect on ammonium removal by zeolite since it can influence both the characters of the exchanging ions and the zeolite itself. The effects of initial $\mathrm{pH}$ values in the range $3 \sim 11$ were investigated. $100 \mathrm{~mL}$ of ammonium solution were agitated with $0.5 \mathrm{~g}$ zeolite at 308K. The experimental results are presented in Fig. 2. As seen from Fig.2, the removal efficiency increased slowly as the $\mathrm{pH}$ was increased from 3 to 6 , reached a maximum value at $\mathrm{pH}$, which is consistent with other studies[10,14,15]. It depicts that the ammonium adsorption onto natural zeolite is a $\mathrm{pH}$-dependent process.

The ammonium removal decreased slightly with decreasing $\mathrm{pH}$ suggested that competitive adsorption between $\mathrm{NH}_{4}{ }^{+}$and $\mathrm{H}^{+}$adsorbed on zeolite occurs[16]. The ionic radius $(0.24 \mathrm{~nm})$ of $\mathrm{H}^{+}$is lower than that of $\mathrm{NH}_{4}^{+}(0.286 \mathrm{~nm})$, which makes $\mathrm{H}^{+}$easily enter pore canal and be adsorbed by zeolite than $\mathrm{NH}_{4}{ }^{+}$. With the increase of $\mathrm{pH}$ value, $\mathrm{H}^{+}$concentration decreases which results in the increase of ammonium adsorption amount of zeolite. The continual increase in $\mathrm{pH}$ reduces ammonium removal, especially at $\mathrm{pH}>9$, likely owing to the fewer ammonium ions presented in alkaline solutions. According to the equilibrium reaction of Bronsted-Lowry acid base reaction, given by Eq.3, ammonium in the bulk solution exists in both ionized and molecular forms. $\mathrm{pH}$ and 
temperature affect the forms of ammonium in solution. The distributions of the free and ionized forms of ammonium can be calculated based on Eq.4-Eq. 6 at $35^{\circ} \mathrm{C}$ [17].

$$
\begin{aligned}
& \mathrm{NH}_{3}+\mathrm{H}_{2} \mathrm{O} \quad \mathrm{NH}_{4}^{+}+\mathrm{OH}^{-} . \\
& {[\mathrm{TAN}]=\left[\mathrm{NH}_{3}-\mathrm{N}\right]+\left[\mathrm{NH}_{4}^{+}-\mathrm{N}\right] .} \\
& \frac{\left[N H_{3}-N\right]}{[T A N]}=10^{p H} \div\left(10^{p H}+e^{(6334 \div(273+T))}\right) . \\
& \frac{\left[N H_{4}^{+}-N\right]}{[T A N]}=e^{(6334 \div(273+T))} \div\left(10^{p H}+e^{(6334 \div(273+T))}\right) .
\end{aligned}
$$

When $\mathrm{pH}<7$, more than $98 \%$ of the ammonium exists in ionized form $\left(\mathrm{NH}_{4}^{+}\right)$; When $\mathrm{pH}$ value approaches 9 , about $46 \%$ of ammonium is still left in ionized form. When $\mathrm{pH}$ approaches 10 , only about $8 \%$ of ammonium is left in ionized form. This observation is consistent with the conclusion in Refs. [12,17,18]. Besides, zeolite can be dissolved at high $\mathrm{pH}$ value[18].

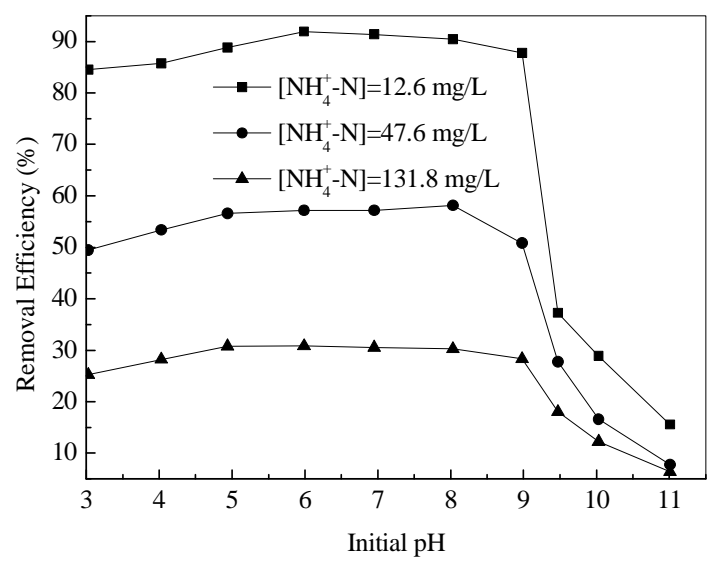

Fig.2 Effect of $\mathrm{pH}$ on ammonium removal by natural zeolite

According to Eqs.4 Eqs. 6 at $35^{\circ} \mathrm{C}$, when pH approaches 10, only about $8 \%$ of ammonium is left in ionized form, and less than $1 \%$ of ammonium is left in ionized form when $\mathrm{pH}$ approaches 11 . If the cation-exchange mechanism occurs only by means of the ammonium ions, the removal rate of ammonia nitrogen should be very low. However, ammonia nitrogen removal rate still reaches $28.8 \%$ and $15 \%$, respectively. These phenomena suggest the interplay of molecular adsorption mechanism. The significance of molecular adsorption was negligible at $\mathrm{pH}<8$. At $\mathrm{pH} 11.0$, molecular adsorption is the dominant mechanism owing to the absence of ionized ammonium in solution. Anyway, the molecular adsorption is of secondary importance and contributed less to the total ammonium removal according to the experimental results under neutral $\mathrm{pH}$ conditions.

It can be seen from Fig.2, the removal rate of ammonia nitrogen by zeolite keeps the high level when the $\mathrm{pH}$ value of solutionin is in the range of 5 9. The $\mathrm{pH}$ value of irrigation drainage is in the range of 8.0 8.8. So, the zeolite can be used to remove ammonium nitrogen of the irrigation drainage in Ningxia irrigation area from the Yellow River.

The effect of the individual presence of competitive cations. Since the irrigation drainages are contaminated by various substances such as inorganic salts, it is important to study the effect of these inorganic salts on the adsorption property of $\mathrm{NH}_{4}{ }^{+}$solutions. Therefore, the solution of sodium chloride $(\mathrm{NaCl})$, potassium chloride $(\mathrm{KCl})$,calcium chloride $\left(\mathrm{CaCl}_{2}\right)$, magnesium chloride $\left(\mathrm{MgCl}_{2}\right)$, sodium nitrate $\left(\mathrm{NaNO}_{3}\right)$, sodium dihydrogen phosphate $\left(\mathrm{NaH}_{2} \mathrm{PO}_{4}\right)$ and sodium sulfate $\left(\mathrm{Na}_{2} \mathrm{SO}_{4}\right)$ was added into the conical flask containing ammonium concentration, respectively. The equivalent concentration of inorganic salt is $0.01 \sim 0.200$ equivalent $\cdot \mathrm{L}^{-1}$ respectively. The constant initial $\mathrm{NH}_{4}{ }^{+}-\mathrm{N}$ concentration is $62.3 \mathrm{mg} \cdot \mathrm{L}^{-1}$. The results can be seen from Fig.3. 
As demonstrated in Fig.3(a), when the initial concentration of $\mathrm{Na}^{+}, \mathrm{K}^{+}, \mathrm{Ca}^{2+}$ and $\mathrm{Mg}^{2+}$ increased from 0.01 to 0.20 equivalent $\cdot \mathrm{L}^{-1}$ in the solution, the adsorption capacities of $\mathrm{NH}_{4}{ }^{+}$on zeolite are significantly reduced by the presence of competitive cations.

The adsorption of $\mathrm{NH}_{4}{ }^{+}$on zeolite is due to the ion exchange reaction between $\mathrm{NH}_{4}{ }^{+}$from aqueous solutions and cations from zeolite, which can be expressed as Eq.7 :

$$
\mathrm{Z}-\mathrm{M}^{\mathrm{n}+}+\mathrm{NH}_{4}{ }^{+} \rightarrow \mathrm{Z}-\mathrm{NH}_{4}{ }^{+}+\mathrm{M}^{\mathrm{n}+}
$$

where $\mathrm{Z}$ - symbolizes the negatively charged functional group of the zeolite. As cations such as $\mathrm{K}^{+}$, $\mathrm{Na}^{+}, \mathrm{Ca}^{2+}$ or $\mathrm{Mg}^{2+}$ in the solution increased, the ammonium adsorption capacity decreased due to the competition with other cations for adsorption sites on the zeolite, and this competition increases with increase in the starting concentration of other cations. In addition, the effect of competition has an order of $\mathrm{K}^{+}>\mathrm{Na}^{+}>\mathrm{Ca}^{2+}>\mathrm{Mg}^{2+}$ for the same initial cation equivalent concentrations. This happens to be the order of the zeolite ion-selective[11]. However, it is different from the result which has been previously reported $[9,12,15]$.This is because different zeolite has different chemical compositions and structures, and thus different cation selectivities.

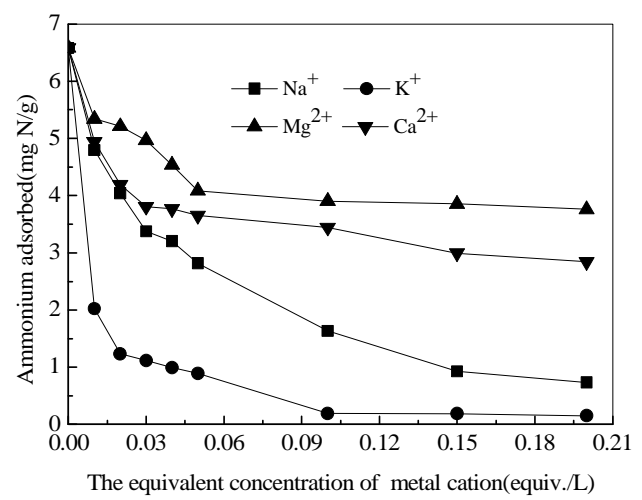

(a) Effect of cations

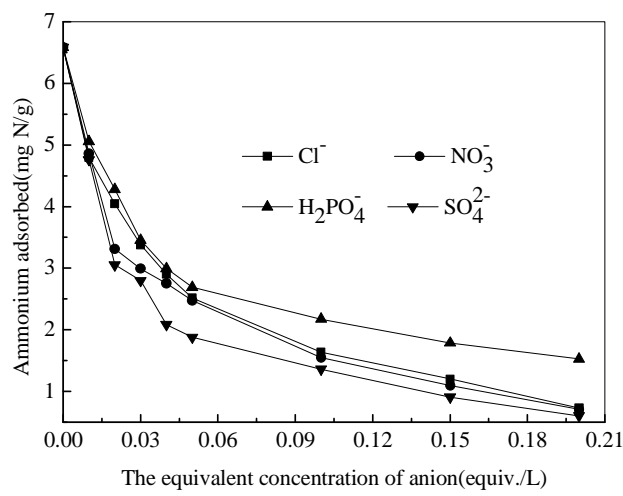

(b) Effect of anions

Fig.3 Effect of co-existing ions on the removal of ammonium nitrogen

Fig.3 (b) shows the influence of anion species on ammonium nitrogen removal by natural zeolite. From Fig.3(b), it can be found that the effect of sulfate present in solution on $\mathrm{NH}_{4}{ }^{+}$removal was greatest, and followed by those of chloride and phosphate. This suggested that the order of anion effect on $\mathrm{NH}_{4}{ }^{+}$removal is $\mathrm{SO}_{4}{ }^{2-}>\mathrm{NO}_{3}{ }^{-}>\mathrm{Cl}^{-}>\mathrm{H}_{2} \mathrm{PO}_{4}{ }^{-}$.

Fig.3 also shows that the zeolite still exhibits high ammonium ion exchange selectivity when equivalent concentrations of coexisting ions are below 0.03 equiv. $\cdot \mathrm{L}^{-1}$. The annual average salinity in drainage of irrigated farmland in the Yellow River irrigation area of Ningxia is in the range of 749 1740 mg $\cdot \mathrm{L}^{-1}$. Therefore, natural zeolites can be used to remove $\mathrm{NH}_{4}{ }^{+}-\mathrm{N}$ in drainage of irrigated.

\section{Conclusions}

Acording to the characteristics of the the subsiding water of cropland in Ningxia irrigation area of the Yellow River, static adsorption experiments were made to remove ammonium nitrogen from the aqueous solution by Baiyin zeolite. Conclusions are as follows:

(1) The ammonium adsorption onto natural zeolite is a $\mathrm{pH}$-dependent process. The cation-exchange mechanism plays an important role at $\mathrm{pH}<8$, while in alkaline solutions, molecular adsorption is the dominant mechanism. The $\mathrm{pH}$ value of irrigation drainage is just within the best $\mathrm{pH}$ range of ammonium removal by Baiyin nature zeolite.

(2) The presence of co-existing ions can significantly influence the removal rate of $\mathrm{NH}_{4}{ }^{+}-\mathrm{N}_{\text {by }}$ the zeolite. The competition orders of cations and anions are $\mathrm{K}^{+}>\mathrm{Na}^{+}>\mathrm{Ca}^{2+}>\mathrm{Mg}^{2+}$ and $\mathrm{SO}_{4}{ }^{2-}>$ $\mathrm{NO}_{3}^{-}>\mathrm{Cl}^{-}>\mathrm{H}_{2} \mathrm{PO}_{4}^{-}$, respectively. However, the natural zeolite still exhibits a high ammonium selectivity for these ions when equivalent concentrations of coexisting ions is below 0.03 equiv./L. 
Based on these results, it can be concluded that natural Baiyin zeolite can be utilized as an alternative sorbent to remove ammonium from the subsiding water of cropland in Yellow River irrigation area of Ningxia.

\section{Acknowledgements}

This work was financially supported by the Foundation of A Hundred Youth Talents Training Program of Lanzhou Jiaotong University.

\section{References}

[1] A. K. Bansiwal, S. S. Rayaalu, N. K. Labhasetwar, A. A. Juwarkar and S. Devotta: Jourrnal of Agriculture and Food Chemistry VoL 54(2006), p. 4773

[2] M. Sprynskyy, M. Lebedynets, R. Zbytniewski, J. Namieśnik and B. Buszewski: Separation and Purification Technology Vol.46 (2005), p.155

[3] G. J. Xiao, Q. Zhang, and Y. Li: Transactions of the CSAE. Vol.26(2010) p.7 (in Chinese)

[4] J. J. Xing, X. B. Qi and Z. D. Huang: Journal of Irrigation and Drainage. Vol.30(2011) , p.72

[5] Q. W. Zhang, H. Zhang, J.Yi, L. G. Luo, A. P .Zhang, F. Wang, R.L. Liu and Z. L Yang.:Acta Scientiae Circumstantiae Vol.30(2010), p.1707 (in Chinese)

[6] H. Liu , S. Peng, L. Shu, T. Chen, T. Bao and R. L. Frost: Journal of colloid and interface science, Vol.390(2013), p.204

[7] Z. Liang and J. R. Ni:Journal of Hazardous Materials. Vol.166(2009), p.52

[8] D. Guaya, C. Valderrama, A. Farran, C.Armijos and J. L. Cortina :Chemical Engineering Journal Vol.271(2015), p.204

[9] L.C. Lei, X.J. Li and X.W. Zhang: Separation and Purification Technology Vol.58(2008), p.359

[10] Q.Du, S. Liu, Z.Cao and Y.Wang :Separation and Purific Technology, Vol. 44(2005), p.229

[11] R. Malekian, J. Abedi-Koupai, S. S. Eslamian: Applied Clay Sciences, Vol.5(2011), p.323

[12] A.M.Yusofa, L.K.Keata, Z.Ibrahimb, Z.A.Majida and N.A.Nizamb : Journal of Hazardous Materials Vol.174 (2010), p.380

[13] Cuiling Zhang, Qing Chang, Jiali Zhang and Caili Gao: Environmental Chemistry Vol. 31(2012), p.1063(in chinese)

[14] N.Widiastuti , H. W.Wu, H. M.Ang and D.K. Zhang :Desalination, Vol.277(2011), p.15

[15] Y.Niu, Y.Zhao, B.Xi, X.Hu, X.Xia, L.Wang and J. Lu :Fresenius Environmental Bulletin, Vol.21 (2012), p.1732

[16] Y.Wang, S.Liu, Z.Xu, T.Han, S.Chuan and T. Zhu: Journal of Hazardous Materials Vol.136(2006), p.735

[17] L. Lin, Z. F.Lei, L.Wang, X. Liu , Y. Zhang, C. L.Wan, D. J. Lee and J. H. Tay :Separation and Purific Technology, Vol. 103(2013), p.15

[18] H.M. Huang, X.M. Xiao, B. Yan and L.P.Yang : Journal of Hazardous Materials Vol.175(2010), p. 247 